\title{
Editorial
}

\section{La Malaria desde la perspectiva de Interculturalidad en Loreto}

En el contexto regional y en el marco de un incremento alarmante de casos de Malaria en zonas rurales de Loreto, es pertinente analizar la Malaria desde la perspectiva de interculturalidad. La Malaria, nombre que proviene de la creencia de que el origen de la enfermedad es un "Mal Aire", es una enfermedad endémica en el Perú y recurrente en departamentos como Madre de Dios y Loreto de mayor concentración de población indígena; sin que esto signifique que la enfermedad esté focalizada o provenga de estas comunidades. El Ministerio de Salud del Perú (MINSA) norma como tratamiento para Malaria causada por Plasmodium vivax a una combinación de medicamentos llamados Cloroquina y Primaquina. Pocos conocen que la población indígena contribuyó a este conocimiento con el uso ancestral del árbol de la Quina, y que actualmente existen otros conocimientos y prácticas indígenas contra la Malaria que aún no han sido estudiados. Es importante remarcar que el conocimiento indígena no se enfoca únicamente en la utilización de plantas, algunas comunidades tienen otras prácticas como secar el cordón umbilical del recién nacido con la finalidad de utilizar la sustancia pulverizada como tratamiento de Malaria.

La convivencia entre la medicina occidental e indígena, revela ciertas dinámicas de interrelación entre las ofertas de salud de la cultura occidental dominante y una aparente pequeña cultura como por ejemplo la Machiguenga, la cual se encuentra ubicada en la Amazonía sur-Peruana. En este caso en particular existen reportes que ante la aparición de sintomatología compatible con Malaria sólo el $54 \%$ de los pobladores Machiguengas acudían al centro de salud, mientras que el $46 \%$ preferían recurrir a baños y brebajes basados en su conocimiento tradicional e identificaron 58 plantas medicinales utilizadas por la población contra la Malaria.

A partir de lo descrito, podemos observar que aplicar una normativa en salud, se basa en el uso de la medicina occidental y hacer "todo lo posible para que la norma se cumpla". Sin embargo, debemos considerar el contexto donde se desarrollan las enfermedades y los cambios que ocurren dentro de ellas, considerar por ejemplo que la vida de las comunidades indígenas que viven en extrema pobreza ha cambiado prácticas y actitudes en los últimos años y ese proceso es continuo. Por citar un ejemplo de éste cambio, desde el punto de vista laboral, existen cada vez más Loretanos de diferentes etnias que abandonan sus comunidades en busca de mejoras en la calidad de vida e ingresan al mundo laboral formal e informal minero, maderero e hidrocarburos (Petroleras). Sin conocer que quizá estas nuevas actividades laborales pueden contribuir indirectamente en la tala de los bosques y la contaminación de las fuentes de agua.

Una de las condiciones que nos permita afirmar que las estrategias inmersas en las políticas de salud aseguren la interculturalidad, es que exista un verdadero contacto de culturas. Y para que sea propiamente una conducta humana establecida, lo que debe ocurrir es un aprendizaje como consecuencia de la socialización con las personas donde se desarrollan las políticas de salud y que ésta socialización sea formal. Aceptar la multiculturalidad loretana y peruana no implica interculturalidad, interculturalidad implica que grupos menores de una cultura mayor sean por lo menos considerados o escuchados. La relación intercultural que observamos en el tratamiento y la oferta de salud en Malaria es armónica, pero aun así se encuentra marcada por desequilibrios que 
han hecho de esta relación, una inequitativa y atentatoria contra el desarrollo de los grupos humanos indígenas.

¿Podríamos quizá hablar de una discriminación de la oferta anti-malárica indígena y de una interculturalidad negativa? Algunos autores han considerado que frente a la interculturalidad negativa tenemos que buscar relacionarnos de tal forma que se amplíe el conocimiento cultural sobre los otros, para que los grupos humanos puedan desenvolverse creativamente y con tolerancia en su ambiente multicultural. Asimismo, podemos hablar de una interculturalidad pasiva frente a una interculturalidad activa. Para lo cual debemos considerar que se debe trabajar activamente y con objetivos claros para estudiar la posibilidad de aplicar tratamientos anti maláricos binomiales.

La Norma Técnica para la transversalización de los enfoques de Derechos Humanos, Equidad de Género e Interculturalidad en Salud, plantea el respeto a los pueblos indígenas, y el respeto por sus costumbres. Sin embargo, la interculturalidad no sólo es escuchar, respetar o tolerar, sino implica un avance cognoscitivo y de comprensión de la cultura indígena como diverso de uno para asegurar que la construcción de la relación intercultural sea sostenible, productiva e ir en el camino planteando ideas nuevas y creativas para la futura investigación. El Estado Peruano se define como democrático y representativo, pero a través del ejemplo planteado vemos como tiene un sello propio para expresar pautas y valores hegemónicos sobre otras culturas escasamente reconocidas en él. Por debilidades propias de las funciones del Estado, ha tenido que pasar 25 años desde la carta de Otawa y desde que la Organización Mundial de la Salud declaró la importancia de incluir los conceptos de equidad e interculturalidad, para que el Estado Peruano adopte y nos presente a la Norma Técnica para la transversalización de los enfoques de Derechos Humanos, Equidad de Género e Interculturalidad en Salud.

El Estado Peruano reconoce que la Malaria es un serio problema en las comunidades indígenas de Loreto, pero no posee información exacta sobre la situación de la salud de la población indígena. La viabilidad futura tiene sus pilares en algunos planes de acción de la Norma Técnica para la transversalización de los enfoques de Derechos Humanos, Equidad de Género e Interculturalidad en Salud como son el diálogo con los pueblos indígenas, la introducción del enfoque intercultural en el sistema de salud el cual permite ampliar investigaciones y proponer estrategias culturalmente apropiadas y el establecimiento de mecanismos para sistematizar prácticas indígenas. Desde una visión global, se debe considerar relevante la necesidad de evitar estereotipos culturales y la creación de nuevas desigualdades en Perú, considerar los efectos de la globalización y sumarnos a la reflexión explícita de la ética y moral.

\section{Dra. Karine Zevallos Villegas \\ Centro de Investigación de Enfermedades Tropicales "Hugo Pesce-Maxime Kuczynski" Instituto Nacional de Salud}

E-mail: kzevallos@ins.gob.pe

*Las opiniones y afirmaciones contenidas en este documento son propias de la autora y no deben interpretarse como posición oficial o que reflejan la opinión del Instituto Nacional de Salud. 